\title{
Can Clouds Improve the Performance of Automated Human Detection in Aerial Images?
}

\author{
TOMASZ NiEDZIELSKI $^{1}$ (D) and MirosŁawa JuRECKA ${ }^{1}$
}

\begin{abstract}
The objective of this paper is to investigate the role of clouds in the effectiveness of automated human detection in aerial imagery acquired by unmanned aerial vehicles (UAVs). The automated processing is carried out with the nested k-means method applied to images taken in poor visibility caused by lowaltitude clouds. Data were acquired during a field experiment carried out in the Izerskie Mountains (southwestern Poland). The fixed-wing UAV took RGB aerial photographs of terrain where persons simulated being lost in the wilderness. The UAV flights were conducted in the morning and around the noon, when clouds reduced clarity of aerial images. Subsequent UAV missions were performed in the afternoon and in the evening, when clouds had no impact on imagery. False hit rates $\geq 50 \%$ correspond to clear imagery ( 8 of 9 non-cloudy cases). In contrast, images impacted by clouds reveal false hit rates $\leq 40 \%$ ( 5 of 7 cloudy cases). Sensitivity analysis, carried out on a basis of artificially blurred imagery, confirms that reduced image clarity may improve automated human detection.
\end{abstract}

Key words: Unmanned aerial vehicle, wilderness search and rescue, image processing, geoinformatics, clouds.

\section{Introduction}

Automated detection of humans in aerial images is one of key elements in wilderness search and rescue (WiSAR) activities. According to Goodrich et al. (2009), there are two search and rescue (SAR) roles, namely information acquisition and information analysis. The use of unmanned aerial vehicles (UAVs) to collect aerial images along with their nearreal-time processing to identify lost persons fits the two roles.

Handling Editor: Prof. Andrzej Icha.

1 Department of Geoinformatics and Cartography, Faculty of Earth Sciences and Environmental Management, University of Wrocław, pl. Uniwersytecki 1, 50-137 Wrocław, Poland. E-mail: tomasz.niedzielski@uwr.edu.pl
The growing popularity of UAVs and the increasing number of UAV operations broaden their use in SAR applications (e.g. Van Tilburg 2017; Silvagni et al. 2017). They include scientific experiments (e.g. Doherty and Rudol 2007; Goodrich et al. 2008; Miller et al. 2008; Molina et al. 2012) as well as comprehensive systems or communities such as for instance: ALCEDO (http://www.alcedo.ethz.ch, access date: 24/09/2017), SHERPA (Marconi et al. 2013), SWARM, also known as SARDrones (http://sardrones.org, access date: 24/09/2017) and SARUAV (Niedzielski et al. 2017; Jurecka and Niedzielski 2017).

To quickly find a person who is lost in the wilderness, human-assisted searches (e.g. Goodrich et al. 2009; Molina et al. 2012) or automated algorithmic searches (e.g. Rudol and Doherty 2008; Flynn and Cameron 2013) are carried out. In the current state of the UAV-based SAR technologies, there is a general consensus that the automated procedures may support human-assisted searches, but cannot fully substitute an expert who operates a sensor (Molina et al. 2012; Niedzielski et al. 2018).

Cloudiness belongs to weather conditions influencing persons' needs for SAR team involvement, and they are often reported as the second group of environmental factors, after darkness, that contributes to the needs for SAR assistance (Gretchen 2004). Thus, SAR operations are likely to be carried out in cloudy weather. When visibility is poor it may constrain making appropriate decisions on where to go, in specific cases leading a person to be lost. In operational SAR missions, clouds lead to considerable limitations, in particular when airborne or satellite sensors are employed (O’Donnell 1999).

Clouds, fog or smoke may impact performance of different cameras, and therefore the presence of such barriers is treated as a disadvantage in remote sensing 
(Oakley and Satherley 1998; Woodell et al. 2015; Gultepe et al. 2009; Djuricic and Jutzi 2013). In the context of UAV-assisted SAR work, bad weather not only influences image clarity but also limits the effectiveness of search through constraining flights and other field activities (Sumimoto et al. 2000; Niedzielski et al. 2018). However, the negative impact of deteriorated image clarity on the usability of such imagery can be reduced by data processing techniques (Steinvall et al. 1999; Woodell et al. 2015; Yuan et al. 2010). In this study, we approach the problem from the opposite perspective and verify the hypothesis that clouds form a natural filter which decreases false hit rates in the process of human detection. To verify the hypothesis, we apply the nested k-means algorithm to detect persons in aerial photographs taken by a UAV during the field experiment in the Izerskie Mountains (southwestern Poland).

\section{Experimental Setup}

The eBee UAV was controlled from a dedicated mobile UAV laboratory (Niedzielski et al. 2017, Fig. 5 therein). The stable altitude of $123 \mathrm{~m}$ above take-off location (ATO) was kept over the entire experiment conducted on 20/10/2016. Aerial images were taken using the visible light Canon S110 RGB camera. The ground resolution of imagery was approximately equal to $4.3 \mathrm{~cm} / \mathrm{px}$. The camera operated in the automatic mode set by the manufacturer. The wavelengths with maximum spectral responses are $660(\mathrm{R}), 520(\mathrm{G})$, and 450 (B). Five persons were located in the field. Three individuals occupied fixed locations over the entire day and the other two persons were UAV operators who kept changing their sites. Figure 1 presents the study area of Polana Izerska and person locations (P1, P2, P3persons at fixed locations who were subjects of detection; P45-UAV operators who were siting or standing very close to each other and their location varied over the day). Polana Izerska is a mountain meadow of size $250 \times 170 \mathrm{~m}$, with elevations ranging from 951 to $976 \mathrm{~m}$ a.s.l., located in the Izerskie Mountains in southwestern Poland.

Polana Izerska is specifically located, approximately $3 \mathrm{~km}$ eastward from Stóg Izerski which is the first orographic barrier for westerly winds that prevail in western Sudetes. As a consequence, low-altitude clouds and fog occur frequently in Polana Izerska. According to Błaś et al. (2002), the area between Stóg Izerski and Polana Izerska is very foggy, with the annual number of days with fog significantly exceeding 200. The UAV missions targeted at person detection are conduced at low altitudes above ground level to ensure high spatial resolution of imagery, with the recommended altitudes between 60 and 100 $\mathrm{m}$ (Goodrich et al. 2008). The weather on 20/10/2016 was typical for the study area. The variable cloud cover over the entire day enabled to collect both cloud-blurred and sharp imagery to allow the comparison.

For each period of day, a single UAV flight was performed to acquire a set of aerial images covering the entire study area. From each set of photographscorresponding to morning, noon, afternoon or evening - we selected four images, the centres of which were located in the closest vicinity of persons P1, P2 and P3 (Fig. 2). Individual aerial images in the central projection, not orthophotos, were subject to further processing.

Over the entire exercise, air temperatures in Polana Izerska varied between 2.7 and $4.7^{\circ} \mathrm{C}$, while sea level pressure was stable and equal to 1014.7-1016.2 $\mathrm{hPa}$ (Table 1). The aerial images acquired in the morning and noon were highly impacted by clouds, while photographs taken in the afternoon and evening were clear due to better visibility. This enables the comparison of the performance of the nested k-means method for clean and cloud-blurred input images.

The analysis of a few meteorological characteristics of weather on 20/10/2016 in Liberec, i.e. the synoptic station no. 11603 (398 m a.s.l.) recognized by the World Meteorological Organization (WMO) and located close (approximately $25 \mathrm{~km}$ ) to the study area, was carried out (Table 2). Stable weather conditions over the region, in which Polana Izerska and Liberec are located, were inferred from the comparison of Tables 1 and 2. Hence, the extrapolation of cloudiness characteristics from Liberec to Polana Izerska was done. The absolute heights of base of lowest clouds were of 698-997 m a.s.l. which, when extrapolated to Polana Izerska, confirms the low-level 


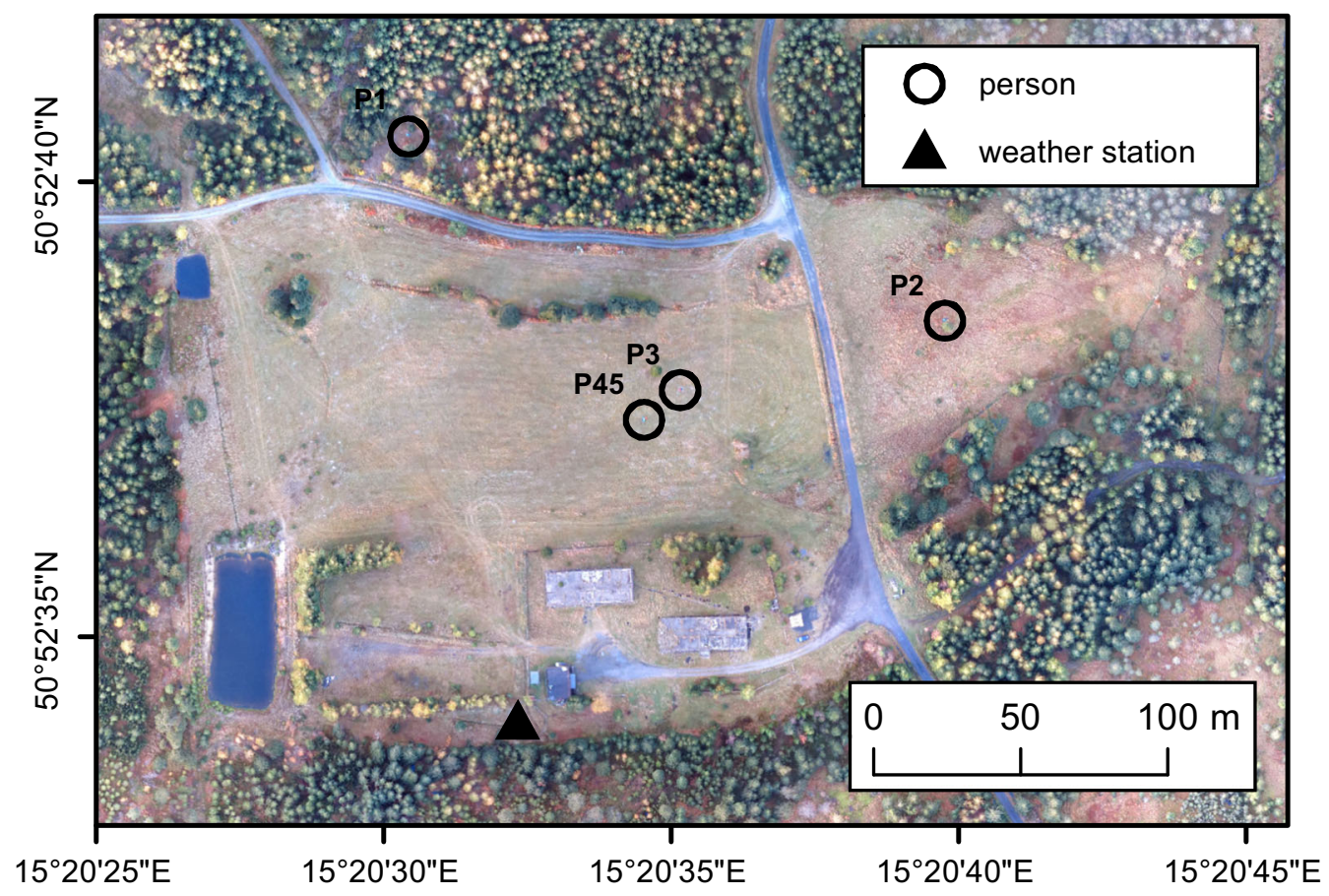

Figure 1

Orthophotomap of study area along with locations of persons who simulated to be lost (codes: P1, P2, P3) and tightly settled two UAV operators (joint code: P45)

cloudiness in the study area. Stratocumulus (Sc) prevailed in the morning and noon, with highly overcast sky reaching the maximum of 8 oktas in the noon. In the afternoon and evening Cumulus $(\mathrm{Cu})$ cooccurred with Sc, reaching the minimum cloudiness of 3 oktas in the evening.

\section{Methods}

The following step-by-step procedure may be employed to investigate the role of clouds in the effectiveness of automated human detection in the UAV-acquired aerial imagery.

- A flight plan over a test area should be prepared so that a UAV operates at altitudes which are suitable for person detection in aerial images (Goodrich et al. 2008; Niedzielski et al. 2018) and flies above persons who pretend being lost in the wilderness.

- A specific day should be chosen so that changes in vegetation do not occur, but the amount of cloud cover varies over this day-ideally with and without cloud impact on visibility of terrain from the UAV.

- The UAV missions ought to be carried out in different cloud-related visibility conditions and JPG aerial photographs of terrain in which these persons are present should be taken.

- (Cloud-blurred imagery) The images with deteriorated clarity should be processed by the nested k-means algorithm to highlight potential locations of persons (nested k-means + true clouds).

- (Clear imagery) The clear images should be processed twofold:

- by the nested k-means algorithm to highlight potential locations of persons (nested k-means + no clouds),

- clear imagery should also be artificially blurred and processed by the nested k-means algorithm to highlight potential locations of persons (nested k-means + artificial clouds). 

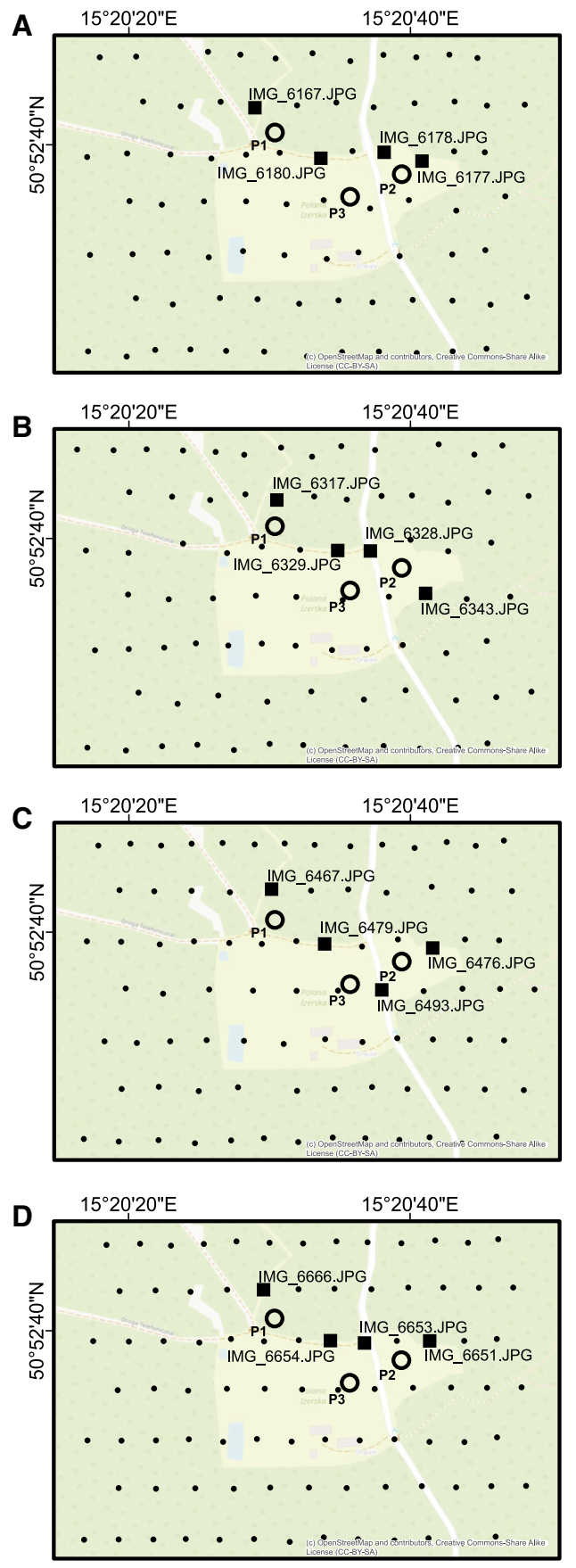

O Person locations $\square$ Centre of chosen images - Centre of images

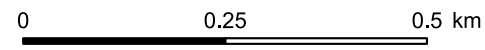

Figure 2

Approximate locations of cameras mounted onboard the UAV along with locations of the selected images $\left(\mathrm{IMG}_{-}\right)$and settled persons (P1, P2, P3) in the morning (a), noon (b), afternoon (c) and evening (d)
Table 1

Selected meteorological characteristics of weather on 20/10/2016 in Polana Izerska (969.8 $\mathrm{m}$ a.s.l.), based on the weather station of Świeradów Forest Inspectorate located within the study area, both at the moments of UAV image acquisition over Polana Izerska and at the closest round hours (see Table 3 for details). Source: Świeradów Forest Inspectorate

\begin{tabular}{llll}
\hline Time UTC & $\begin{array}{l}\text { Temperature } \\
\left({ }^{\circ} \mathrm{C}\right)\end{array}$ & $\begin{array}{l}\text { Pressure } \\
(\mathrm{hPa})\end{array}$ & $\begin{array}{l}\text { Approximate sea level } \\
\text { pressure }(\mathrm{hPa})\end{array}$ \\
\hline 06:48:00 & 2.7 & 902.3 & 1016.1 \\
07:00:00 & 2.8 & 902.4 & 1016.2 \\
09:48:00 & 3.8 & 902.3 & 1015.6 \\
10:00:00 & 4.6 & 902.3 & 1015.2 \\
12:36:00 & 4.7 & 902.0 & 1014.9 \\
13:00:00 & 4.7 & 902.0 & 1014.9 \\
15:00:00 & 4.6 & 901.8 & 1014.7 \\
15:12:00 & 4.6 & 901.8 & 1014.7 \\
\hline
\end{tabular}

The nested k-means method assumes the segmentation of an aerial image into squares (moving windows), built with superimposing stripes to avoid splitting person's signal into two segments. The nesting is based on performing three consecutive tests in each segment. The first test uses the k-means method on a three-dimensional space of colours (RGB) to identify the most unique class, highly coherent in terms of colour composition. The second test uses the k-means method on a two-dimensional space of locations to check if the previously selected class is spatially coherent. The third test is applied to check if the size of the class fits the typical areas of standing or lying person. The details about the nested k-means method can be found in the paper by Niedzielski et al. (2017, Fig. 1 therein).

If the first test produces a flag 0 , the overall output in a given segment is also equal to 0 (no person found). If the first test ends up with a flag 1 (person is likely to be present in a segment), the second test is run. If the second test produces a flag 0 , the overall output in a segment is 0 (no person found). However, if the second test produces a flag 1 (person is likely to be present in a segment), the third test is run. If its application ends up with a flag 0 , the overall procedure in a studied segment gives 0 (no person found). In contrast, if the third test produces a flag 1 , the overall output in a given segment is equal to 1 (person found). The segment which gets 1 in the third test is hereinafter known as "find segment" 
Table 2

Selected meteorological characteristics of weather on 20/10/2016 in Liberec, based on the World Meteorological Organization (WMO) synoptic station no. 11603 (398 $\mathrm{m}$ a.s.l.) located in the vicinity of the study area, at the closest times to the moments of UAV image acquisition over Polana Izerska (see Tables 1, 3 for details). Source: http://www.ogimet.com (access date: 04/10/2017)

\begin{tabular}{|c|c|c|c|c|c|c|c|c|c|}
\hline $\begin{array}{l}\text { Time } \\
\text { UTC }\end{array}$ & $\begin{array}{l}\text { Height of base } \\
\text { of lowest cloud } \\
\text { (m) }\end{array}$ & $\begin{array}{l}\text { Absolute height of } \\
\text { base of lowest cloud } \\
\text { (m a.s.l.) }\end{array}$ & $\begin{array}{l}\text { Total } \\
\text { cloud } \\
\text { cover } \\
\text { (oktas) }\end{array}$ & $\begin{array}{l}\text { Total low } \\
\text { cloud cover } \\
\text { (oktas) }\end{array}$ & $\begin{array}{l}\text { Horizontal } \\
\text { visibility } \\
(\mathrm{km})\end{array}$ & $\begin{array}{l}\text { Low- } \\
\text { level } \\
\text { cloud } \\
\text { type }\end{array}$ & $\begin{array}{l}\text { Temperature } \\
\left({ }^{\circ} \mathrm{C}\right)\end{array}$ & $\begin{array}{l}\text { Pressure } \\
(\mathrm{hPa})\end{array}$ & $\begin{array}{l}\text { Sea level } \\
\text { pressure } \\
(\mathrm{hPa})\end{array}$ \\
\hline 07:00:00 & $300-599$ & 698-997 & 5 & 4 & 23 & $\mathrm{Sc}$ & 7.0 & 967.8 & 1016.0 \\
\hline 10:00:00 & $300-599$ & $698-997$ & 8 & 8 & 15 & $\mathrm{Sc}$ & 8.1 & 967.7 & 1015.7 \\
\hline $13: 00: 00$ & $300-599$ & $698-997$ & 5 & 4 & 25 & $\mathrm{Cu}, \mathrm{Sc}$ & 9.1 & 966.8 & 1014.6 \\
\hline 15:00:00 & $300-599$ & 698-997 & 3 & 3 & 27 & $\mathrm{Sc}, \mathrm{Cu}$ & 8.0 & 966.4 & 1014.4 \\
\hline
\end{tabular}

or "highlighted segment" (Niedzielski et al. 2017, Fig. 3 therein).

An aerial photograph processed using the nested $\mathrm{k}$-means algorithm produces a new image which is a composition of the original photo and transparent squared segments. The intensity of segment greyness corresponds to a probability of finding a person (zero probability does not imply image colouring). There are three statistics associated with the analysis of a single aerial photograph (Fig. 3): (1) detection rate (the percentage of persons who were found, i.e.
$100 \% \times$ the number of correctly highlighted segments divided by a true number of persons within the entire image), (2) false hit rate (the percentage of highlighted segments which did not detect a person, i.e. $100 \% \times$ the number of incorrect or simply overestimated highlighted segments divided by the total number of highlighted segments) and (3) percentage of segments suggested to be searched, abbreviated as POSSTBS $(100 \% \times$ the number of highlighted segments divided by all the possible segments within the entire image). The POSSTBS

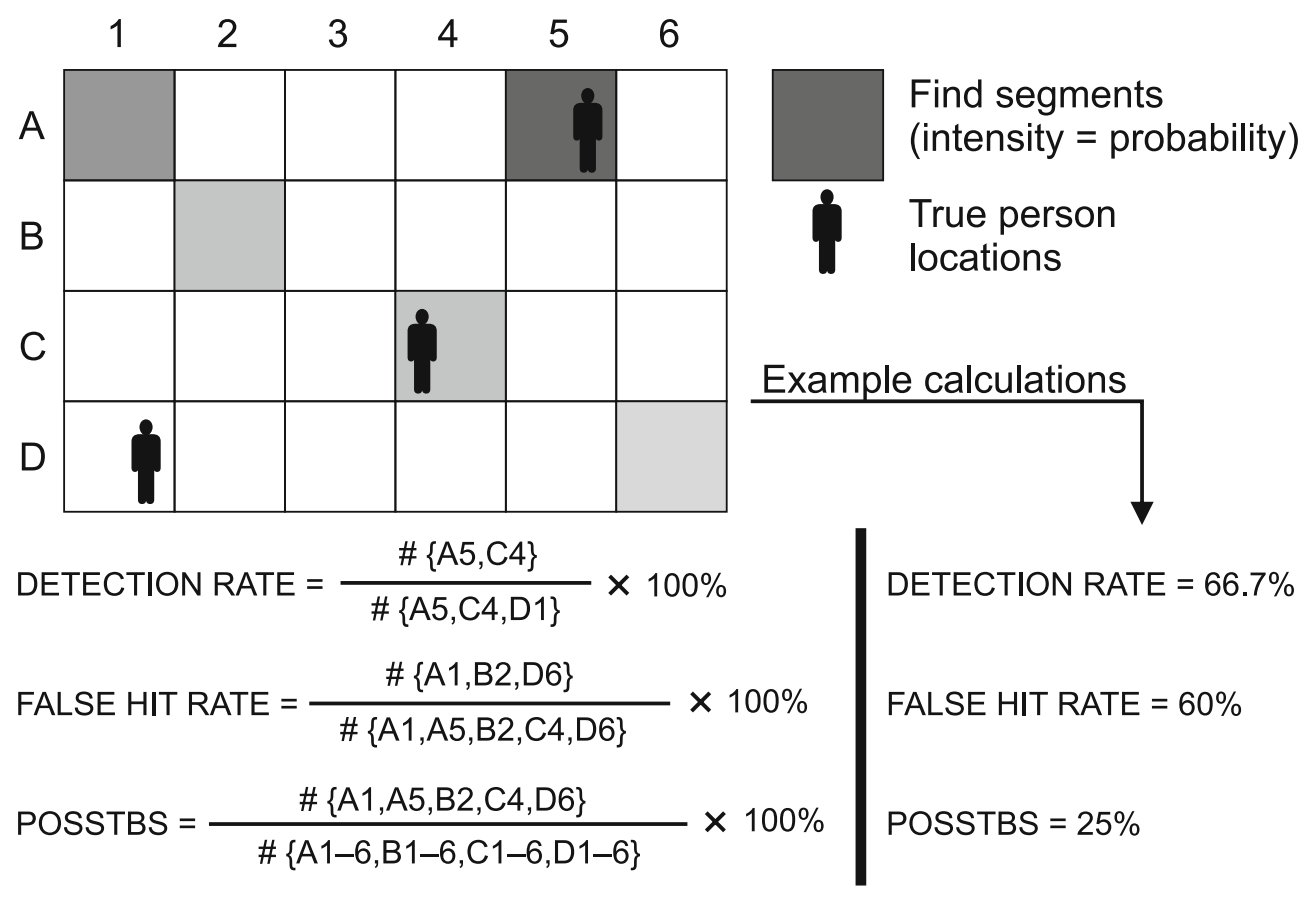

Figure 3

Statistical measures of person detection performance: a graphical presentation 
statistics measures the fraction of terrain area which is advised to be searched by ground searchers.

\section{Results}

\subsection{Detection Based on Cloud-Blurred Images}

Figures 4 and 5 show the selected images, the locations of which are marked in Fig. 2, with superimposed highlighted segments. Figure 4 (left column) presents the performance of the nested k-means method for images targeted at the person $\mathrm{P} 1$, with no other human individuals present in the scene. Figure 4 (right column) offers the same presentation for the person P2 who also was the only one person in the scene. Figure 5 is targeted at the person $\mathrm{P} 3$, however, the other persons $\mathrm{P} 1$ or $\mathrm{P} 2$ and, in addition, the two UAV operators were also recorded in the images. The UAV operators were standing or sitting very close to each other, therefore they were treated as a single person P45. The low-level Sc clouds blurred meaningful parts of background images in first two rows of Figs. 4 and 5 (morning, noon), while $\mathrm{Cu}$ and $\mathrm{Sc}$ clouds did not deteriorate the clearness of background images in third and fourth rows of Figs. 4 and 5 (afternoon, evening).

For each aerial photograph under study, Table 3 juxtaposes information on image acquisition features (actual cloudiness which may constrain the view, code of targeted person, image number, period of day, detailed data collection times in CEST and UTC, number and codes of true persons in image) as well as on the performance of the nested k-means method (number of find segments, detection rate, false fit rate, POSSTBS). The records in Table 3 are grouped into four sets which correspond to observations of the similar scene containing the same person or persons (with one exception) in four periods of day covering cloudy and non-cloudy conditions. It should be noted that in all cloudy situations different levels of transparency through clouds were recorded, however, in the worst visibility cases the terrain view from the UAV was highly blurred but still visible.

The person P1 (images: 6167, 6317, 6467, 6666) was detected with rates of $100 \%$ for cloudy conditions, however, false hit rates were low $(0 \%)$ when cloud cover was continuous and high $(85.7 \%)$ when patchy clouds occurred. The latter statistics show
Figure 4

The UAV-acquired images with superimposed highlighted segments: left column-observations of the person P1 in four periods of day, right column-observations of the person P2 in four periods of day. Letters A-F mark characteristic points in geographical space to enable orientation

overestimation of find segments, probably due to the fact that cloud patches occupied minor parts of the image (the case is therefore similar to the non-cloudy situation). When clouds did not form a barrier between the terrain and the camera, the nested $\mathrm{k}$-means method returned either perfect fit $(100 \%$ detection rate, $0 \%$ false hit rate, $0.5 \%$ POSSTBS) or incorrect result $(0 \%$ detection rate, $100 \%$ false fit rate). Overall, the analysis of four images targeted at the person P1 did not convey a clear message as to whether cloud cover improved the performance of person detection using the nested k-means method.

In contrast, the person P2 (images: 6177, 6343, 6476, 6651) was correctly detected with $100 \%$ detection rates in the four photographs, with and without cloud impact. However, the false hit rates were of $0 \%$ for cloudy conditions (patchy and continuous cover) and increased to $66.7 \%$ when images became clean after the clouds departed. That impacted the POSSTBS values which grew from 0.5 to $1.5 \%$ when switching from cloudy to non-cloudy conditions.

Even more pronounced evidence for the positive role of transparent clouds in improving the performance of human detection using the nested k-means approach is provided by the analysis of images targeted at the person P3 and, additionally, the person P1 and tightly settled two UAV operators P45 (images: 6180, 6329, 6479, 6654). The case covers two analyses with input images blurred by continuous clouds and the other two images without any cloud impacts. The number of highlighted segments was low for cloudy scenes, with high detection rate of $100 \%$ and false hit rates ranging between 0 and $40 \%$. The values of statistics deteriorated when clean images were analysed. Indeed, detection rates varied between 100 and $66.7 \%$, false hit rates were as high as 57.1 and $80 \%$. The POSSTBS values confirmed the overrepresentation of highlighted segments for non-cloudy images (3.4 and 4.9\%) in comparison to the cloudy scenes (1.5 and $2.5 \%$ ). 

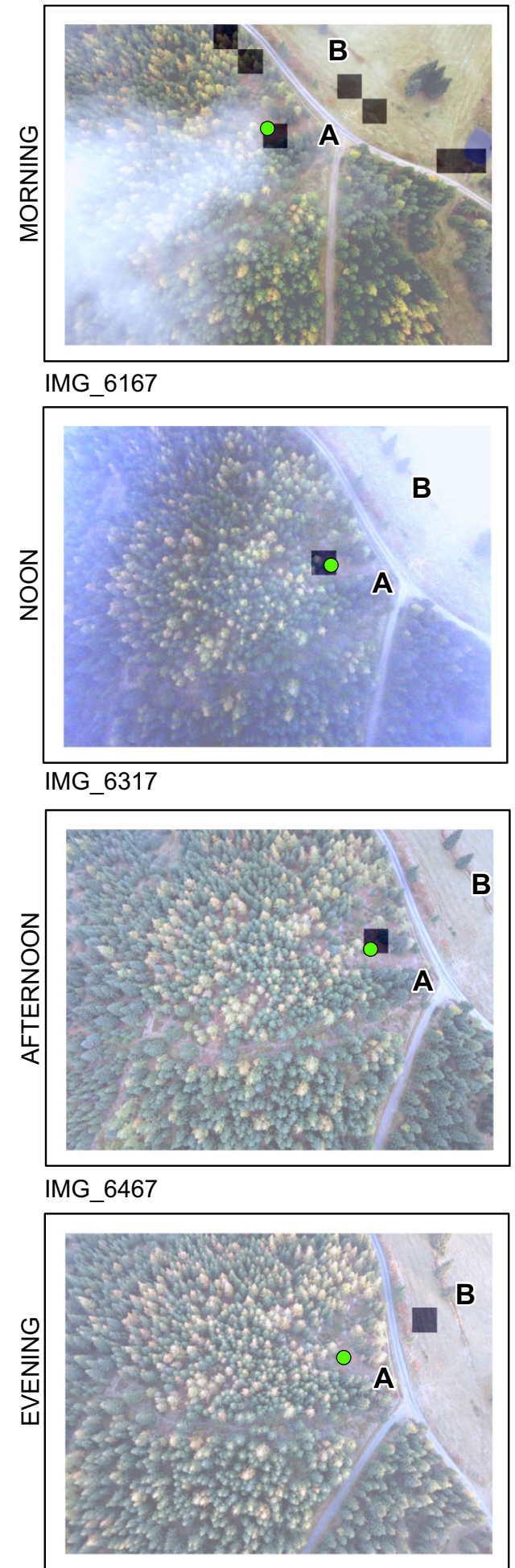

IMG_6666

A, B, C, D, E, F - characteristic points

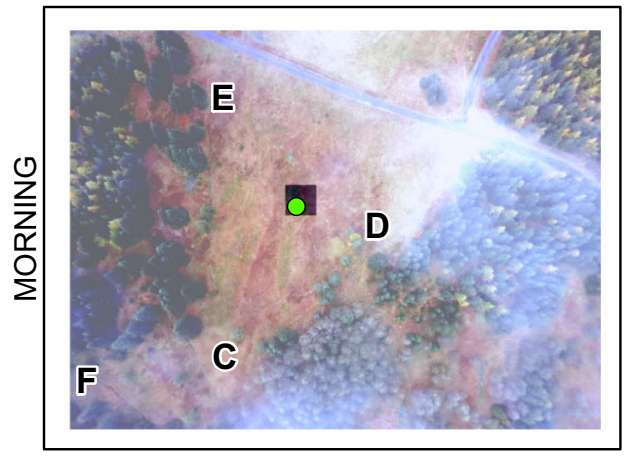

$$
\text { IMG_6177 }
$$
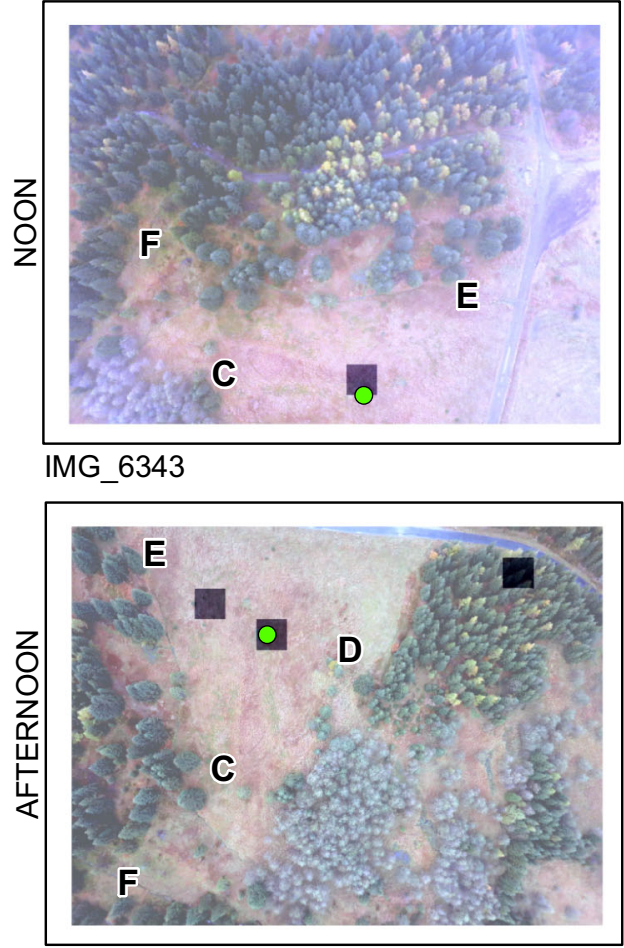

IMG_6476

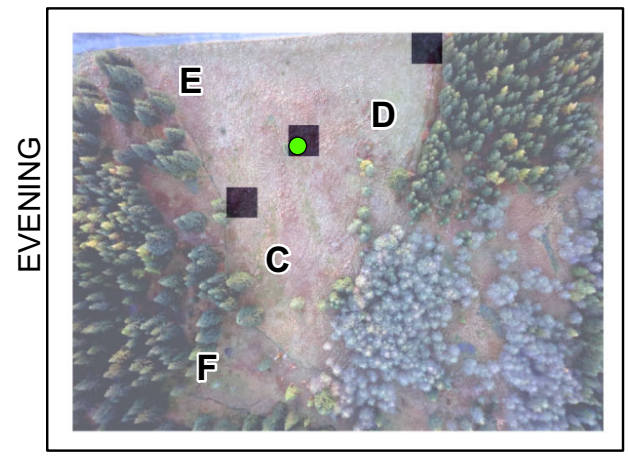

IMG_6651

- locations of persons 


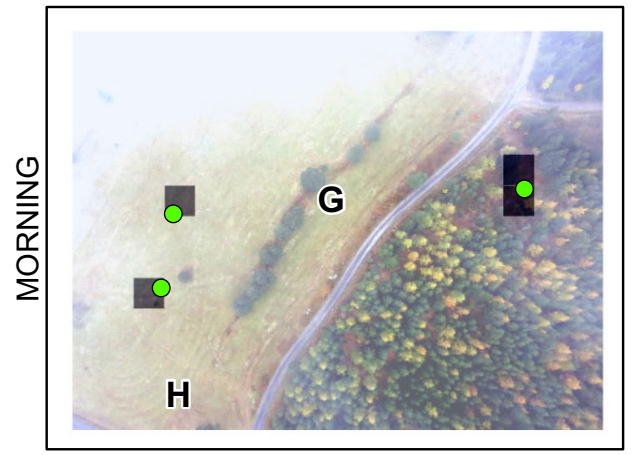

IMG_6180

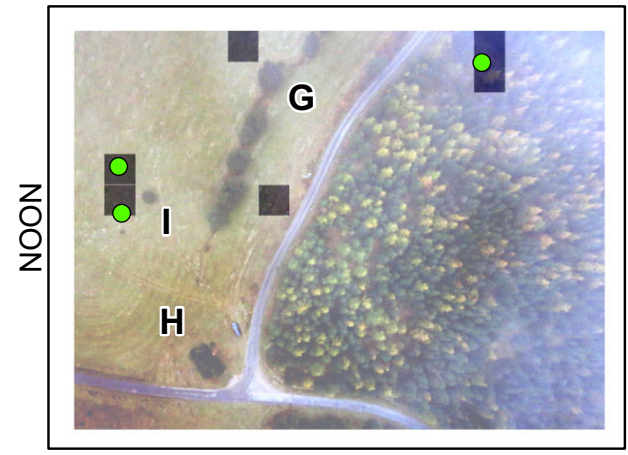

$$
\text { IMG_6329 }
$$

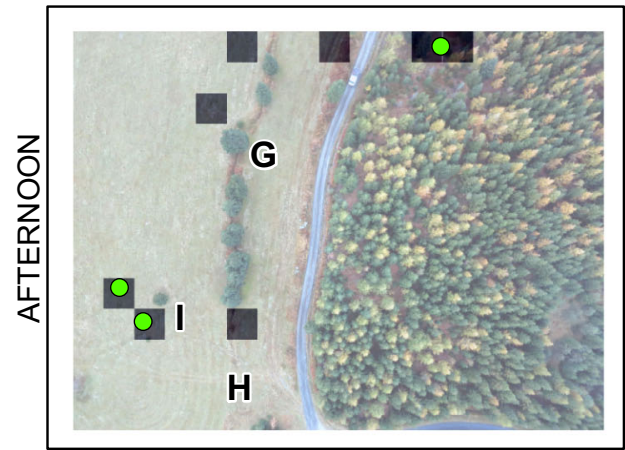

IMG_6479

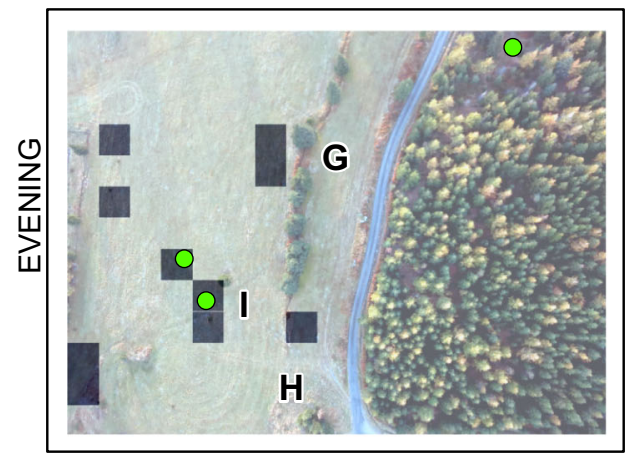

IMG_6654

G, H, I, J - characteristic points

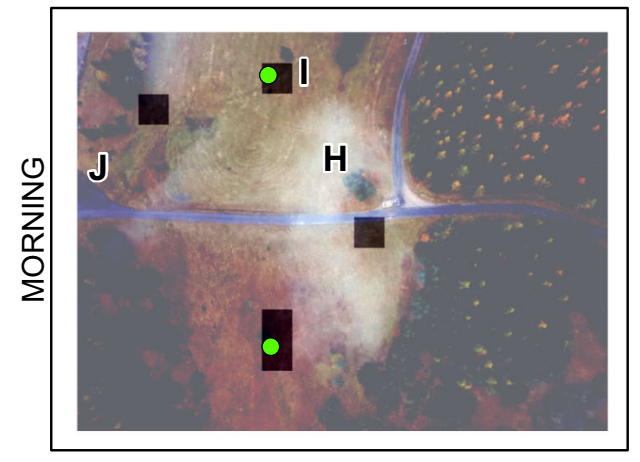

IMG_6178
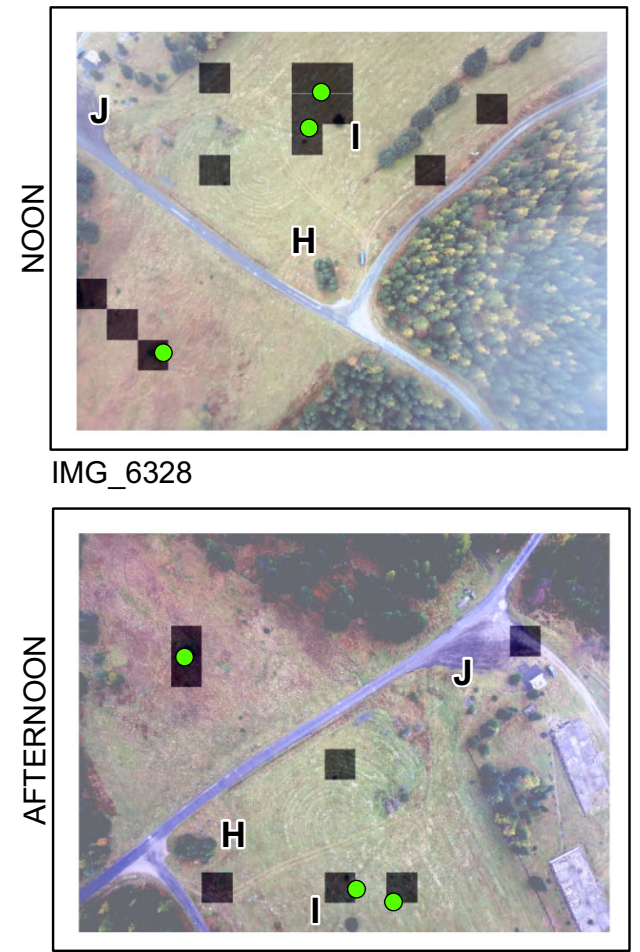

IMG_6493

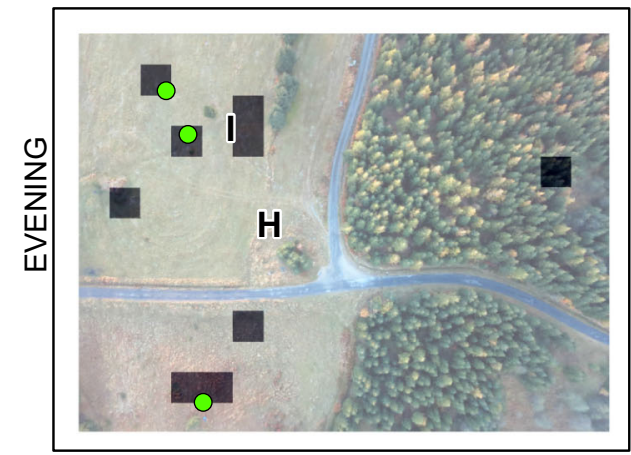

IMG 6653

locations of persons 
Figure 5

The UAV-acquired images with superimposed highlighted segments: left column-observations of the persons P3, P1 and P45 in four periods of day, right column-observations of the person P3, P2, P45 in four periods of day. Letters G-J mark characteristic points in geographical space to enable orientation

The other scene targeted at the person P3, also including the signals of P2 and P45 (images: 6178, $6328,6493,6653$ ) does not enable the comparison between cloudy and non-cloudy cases. Patchy clouds were only present in the image no. 6178, but it did not captured P45 which constrains the thorough comparison. However, a lesson can be learnt from the analysis of non-cloudy situations. Although high detection rates of $100 \%$ were revealed, the image processing concurrently led to considerable false hit rates ranging from 50 to $66.7 \%$.

The entire analysis shows that the increased false hits rates seem to characterize the analyses performed using clean images ( 8 of 9 non-cloudy cases reveal false hit rates $\geq 50 \%$ ). In contrast, low false hit rates tend to correspond to the analyses carried out using cloud-blurred images ( 5 of 7 cloudy cases reveal false hit rates $\leq 40 \%$ ). Therefore, the presence of transparent cloud cover is likely to reduce false hits and overrepresentation of highlighted segments.

\subsection{Detection Based on Artificially Blurred Images}

To confirm the above-mentioned findings obtained on a basis of cloud-blurred images, a numerical experiment was carried out. From the analyses presented in Figs. 4 and 5, clear imagesthose for which the nested k-means algorithm produced high false hit rates and potential locations were overrepresented (POSSRBS $\geq 2.9$ )—were selected (noon image: 6328; afternoon images: 6479, 6493; evening images: 6654, 6653). They were pre-processed by superimposing a new uniform white layer with different levels of transparency applied $(25,50,75,80$ and $90 \%)$. As a result, the clarity of original image was artificially deteriorated to simulate the effect of cloud blurriness (Fig. 6). Such artificially blurred images became subject to further processing using the nested k-means approach. Table 4 juxtaposes performance statistics of the nested k-means algorithm for these five images and

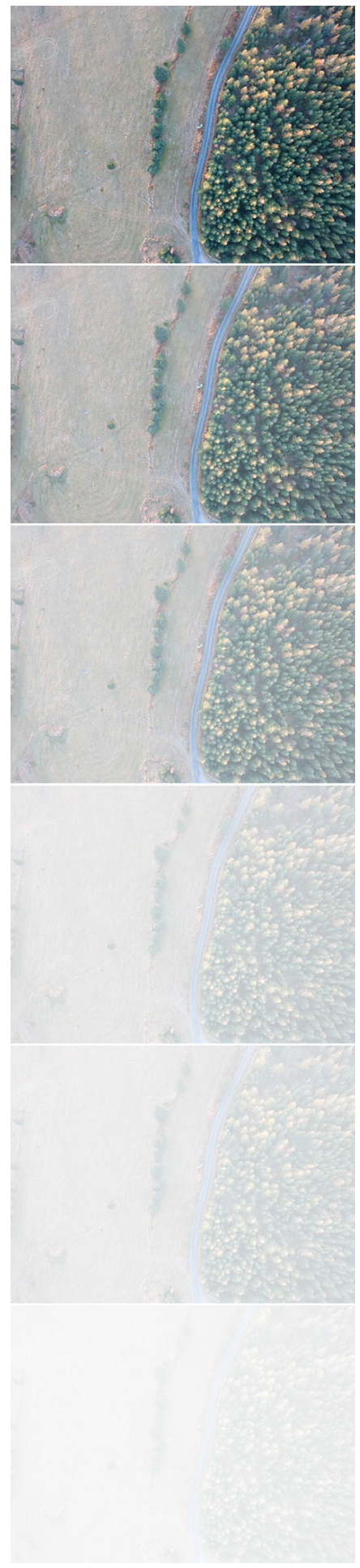

Figure 6

Example of artificial blurring of image no. 6654 performed by superimposing a white layer with dissimilar transparencies (top to bottom): $0,25,50,75,80,90 \%$ 
Table 3

Performance of the nested k-means method in detecting persons in UAV-taken aerial images acquired through continuous clouds (low visibility over the entire image) and patchy clouds (low visibility in parts of image) versus the skills of the same algorithm run using clean input photographs

\begin{tabular}{|c|c|c|c|c|c|c|c|c|c|c|}
\hline $\begin{array}{l}\text { Cloud } \\
\text { cover in } \\
\text { image }\end{array}$ & $\begin{array}{l}\text { Vicinity of } \\
\text { settled } \\
\text { person }\end{array}$ & $\begin{array}{l}\text { Image } \\
\text { number }\end{array}$ & $\begin{array}{l}\text { Period of } \\
\text { day }\end{array}$ & $\begin{array}{l}\text { Time } \\
\text { CEST }\end{array}$ & $\begin{array}{l}\text { Time } \\
\text { UTC }\end{array}$ & $\begin{array}{l}\text { True number of } \\
\text { persons in image }\end{array}$ & $\begin{array}{l}\text { Number of } \\
\text { find } \\
\text { segments }\end{array}$ & $\begin{array}{l}\text { Detection } \\
\text { rate }(\%)\end{array}$ & $\begin{array}{l}\text { False hit } \\
\text { rate }(\%)\end{array}$ & $\begin{array}{l}\text { POSSTBS } \\
(\%)\end{array}$ \\
\hline Patchy & $\mathrm{P} 1$ & 6167 & Morning & $08: 41: 39$ & $06: 41: 39$ & $1(\mathrm{P} 1)$ & 7 & 100 & 85.7 & 3.4 \\
\hline Continuous & P1 & 6317 & Noon & $11: 44: 23$ & $09: 44: 23$ & $1(\mathrm{P} 1)$ & 1 & 100 & 0 & 0.5 \\
\hline None & $\mathrm{P} 1$ & 6467 & Afternoon & $14: 34: 57$ & $12: 34: 57$ & $1(\mathrm{P} 1)$ & 1 & 100 & 0 & 0.5 \\
\hline None & $\mathrm{P} 1$ & 6666 & Evening & $17: 12: 55$ & $15: 12: 55$ & $1(\mathrm{P} 1)$ & 1 & 0 & 100 & 0.5 \\
\hline Patchy & $\mathrm{P} 2$ & 6177 & Morning & $08: 42: 29$ & $06: 42: 29$ & $1(\mathrm{P} 2)$ & 1 & 100 & 0 & 0.5 \\
\hline Continuous & $\mathrm{P} 2$ & 6343 & Noon & $11: 46: 28$ & $09: 46: 28$ & $1(\mathrm{P} 2)$ & 1 & 100 & 0 & 0.5 \\
\hline None & $\mathrm{P} 2$ & 6476 & Afternoon & $14: 35: 45$ & $12: 35: 45$ & $1(\mathrm{P} 2)$ & 3 & 100 & 66.7 & 1.5 \\
\hline None & $\mathrm{P} 2$ & 6651 & Evening & $17: 11: 50$ & $15: 11: 50$ & $1(\mathrm{P} 2)$ & 3 & 100 & 66.7 & 1.5 \\
\hline Continuous & $\mathrm{P} 3$ & 6180 & Morning & $08: 42: 39$ & $06: 42: 39$ & $3^{\mathrm{a}}(\mathrm{P} 3, \mathrm{P} 1, \mathrm{P} 45)$ & $3^{\mathrm{b}}$ & $100^{\mathrm{ab}}$ & $0^{\mathrm{ab}}$ & $1.5^{\mathrm{b}}$ \\
\hline Continuous & P3 & 6329 & Noon & $11: 45: 23$ & $09: 45: 23$ & $3^{\mathrm{a}}(\mathrm{P} 3, \mathrm{P} 1, \mathrm{P} 45)$ & $5^{\mathrm{b}}$ & $100^{\mathrm{ab}}$ & $40.0^{\mathrm{ab}}$ & $2.5^{\mathrm{b}}$ \\
\hline None & $\mathrm{P} 3$ & 6479 & Afternoon & $14: 35: 58$ & $12: 35: 58$ & $3^{\mathrm{a}}(\mathrm{P} 3, \mathrm{P} 1, \mathrm{P} 45)$ & $7^{\mathrm{b}}$ & $100^{\mathrm{ab}}$ & $57.1^{\mathrm{ab}}$ & $3.4^{\mathrm{b}}$ \\
\hline None & P3 & 6654 & Evening & $17: 12: 01$ & $15: 12: 01$ & $3^{\mathrm{a}}(\mathrm{P} 3, \mathrm{P} 1, \mathrm{P} 45)$ & 10 & $66.7^{\mathrm{a}}$ & $80.0^{\mathrm{a}}$ & 4.9 \\
\hline Patchy & $\mathrm{P} 3$ & 6178 & Morning & $08: 42: 33$ & $06: 42: 33$ & $2(\mathrm{P} 3, \mathrm{P} 2)$ & $4^{\mathrm{b}}$ & $100^{\mathrm{b}}$ & $50.0^{\mathrm{b}}$ & $2.0^{\mathrm{b}}$ \\
\hline None $^{\mathrm{c}}$ & $\mathrm{P} 3$ & 6328 & Noon & $11: 45: 19$ & $09: 45: 19$ & $3^{\mathrm{a}}(\mathrm{P} 3, \mathrm{P} 2, \mathrm{P} 45)$ & $9^{\mathrm{b}}$ & $100^{\mathrm{ab}}$ & $66.7^{\mathrm{ab}}$ & $4.4^{\mathrm{b}}$ \\
\hline None & $\mathrm{P} 3$ & 6493 & Afternoon & $14: 36: 59$ & $12: 36: 59$ & $3^{\mathrm{a}}(\mathrm{P} 3, \mathrm{P} 2, \mathrm{P} 45)$ & $6^{\mathrm{b}}$ & $100^{\mathrm{ab}}$ & $50.0^{\mathrm{ab}}$ & $2.9^{\mathrm{b}}$ \\
\hline None & $\mathrm{P} 3$ & 6653 & Evening & $17: 11: 57$ & $15: 11: 57$ & $3^{\mathrm{a}}(\mathrm{P} 3, \mathrm{P} 2, \mathrm{P} 45)$ & $8^{b}$ & $100^{\mathrm{ab}}$ & $62.5^{\mathrm{ab}}$ & $3.9^{\mathrm{b}}$ \\
\hline
\end{tabular}

Statistics are defined in Sect. 3 and in Fig. 3

P1—settled person wearing blue jacket

P2 - settled person wearing blue jacket

P3—settled person wearing red jacket

P45-two UAV operators sitting/standing tightly in bunch, wearing blue and red jackets (two people treated as one person)

${ }^{\text {a }}$ Statistics corrected due to the assumption that P45 is a single person,

${ }^{\mathrm{b}}$ Statistics corrected due to person split into 2-4 adjacent segments (overlapping stripes-see Sect. 3),

'Small cloud patch near image corner (no impact on persons' view)

different levels of transparency. It is apparent from Table 4 that there exist certain levels of blurriness for which false hit rates are minimized. Indeed, these minimum values were attained for transparencies ranging from 25 to $75 \%$.

\subsection{Interpretation}

It is known that the presence of atmospheric aerosols leads to the reduction of image contrast and colour. Aerosol particles cause light to scatter when travelling toward the camera and, additionally, weaken the light signal reflected from the ground (Oakley and Satherley 1998; Gultepe et al. 2009). Our analysis based on input images blurred by true clouds and the scrutiny based on the artificially blurred input photos revealed a decrease in false hit rates of human detection performed with the nested k-means method. Clouds and their artificial equivalents cause a significant reduction in contrast and colour of imagery, decreasing a number of details. Such details may be incorrectly classified as persons by the nested k-means method, contributing to false hits where no person is actually present. The clouds and their artificial equivalents work as filters which remove noise from imagery. As a result, the most evident signals remain visible. Hence, the nested k-means method seems to perform better because false hit rates are decreased due to reduced clarity of images. However, as shown above in the experiment with artificially blurred images, the effect of decreasing a number of false hits occurs to a certain level of 
Table 4

Performance of the nested $k$-means method in detecting persons in artificially blurred UAV-taken aerial images

\begin{tabular}{|c|c|c|c|c|c|}
\hline $\begin{array}{l}\text { Image } \\
\text { number }\end{array}$ & $\begin{array}{l}\text { Transparency } \\
(\%)\end{array}$ & $\begin{array}{l}\text { True } \\
\text { number } \\
\text { of } \\
\text { persons }\end{array}$ & $\begin{array}{l}\text { Number } \\
\text { of find } \\
\text { segments }\end{array}$ & $\begin{array}{l}\text { Detection } \\
\text { rate }(\%)\end{array}$ & $\begin{array}{l}\text { False } \\
\text { hit rate } \\
(\%)\end{array}$ \\
\hline $6328^{*}$ & 0 & $3^{\mathrm{a}}$ & $9^{\mathrm{b}}$ & $100^{\mathrm{ab}}$ & $66.7^{\mathrm{ab}}$ \\
\hline $6328^{*}$ & 25 & $3^{\mathrm{a}}$ & $5^{\mathrm{b}}$ & $100^{\mathrm{ab}}$ & $40.0^{\mathrm{ab}}$ \\
\hline $6328^{*}$ & 50 & $3^{\mathrm{a}}$ & $7^{\mathrm{b}}$ & $100^{\mathrm{ab}}$ & $57.1^{\mathrm{ab}}$ \\
\hline $6328^{*}$ & 75 & $3^{\mathrm{a}}$ & $8^{b}$ & $100^{\mathrm{ab}}$ & $62.5^{\mathrm{ab}}$ \\
\hline $6328 *$ & 80 & $3^{\mathrm{a}}$ & $11^{\mathrm{b}}$ & $100^{\mathrm{ab}}$ & $72.7^{\mathrm{ab}}$ \\
\hline $6328^{*}$ & 90 & $3^{\mathrm{a}}$ & $10^{\mathrm{b}}$ & $100^{\mathrm{ab}}$ & $70.0^{\mathrm{ab}}$ \\
\hline 6479 & 0 & $3^{\mathrm{a}}$ & $7^{\mathrm{b}}$ & $100^{\mathrm{ab}}$ & $57.1^{\mathrm{ab}}$ \\
\hline 6479 & 25 & $3^{\mathrm{a}}$ & $7^{\mathrm{b}}$ & $66.7^{\mathrm{ab}}$ & $71.4^{\mathrm{ab}}$ \\
\hline 6479 & 50 & $3^{\mathrm{a}}$ & $7^{\mathrm{b}}$ & $100^{\mathrm{ab}}$ & $57.1^{\mathrm{ab}}$ \\
\hline 6479 & 75 & $3^{\mathrm{a}}$ & $5^{\mathrm{b}}$ & $66.7^{\mathrm{ab}}$ & $60.0^{\mathrm{ab}}$ \\
\hline 6479 & 80 & $3^{\mathrm{a}}$ & $5^{\mathrm{b}}$ & $66.7^{\mathrm{ab}}$ & $60.0^{\mathrm{ab}}$ \\
\hline 6479 & 90 & $3^{\mathrm{a}}$ & $8^{\mathrm{b}}$ & $66.7^{\mathrm{ab}}$ & $75.0^{\mathrm{ab}}$ \\
\hline 6493 & 0 & $3^{\mathrm{a}}$ & $6^{\mathrm{b}}$ & $100^{\mathrm{ab}}$ & $50.0^{\mathrm{ab}}$ \\
\hline 6493 & 25 & $3^{\mathrm{a}}$ & $5^{\mathrm{b}}$ & $100^{\mathrm{ab}}$ & $40.0^{\mathrm{ab}}$ \\
\hline 6493 & 50 & $3^{\mathrm{a}}$ & $5^{\mathrm{b}}$ & $100^{\mathrm{ab}}$ & $40.0^{\mathrm{ab}}$ \\
\hline 6493 & 75 & $3^{\mathrm{a}}$ & $5^{\mathrm{b}}$ & $100^{\mathrm{ab}}$ & $40.0^{\mathrm{ab}}$ \\
\hline 6493 & 80 & $3^{\mathrm{a}}$ & $7^{\mathrm{b}}$ & $100^{\mathrm{ab}}$ & $57.1^{\mathrm{ab}}$ \\
\hline 6493 & 90 & $3^{\mathrm{a}}$ & $10^{\mathrm{b}}$ & $100^{\mathrm{ab}}$ & $70.0^{\mathrm{ab}}$ \\
\hline 6654 & 0 & $3^{\mathrm{a}}$ & 10 & $66.7^{\mathrm{a}}$ & $80.0^{\mathrm{a}}$ \\
\hline 6654 & 25 & $3^{\mathrm{a}}$ & 9 & $66.7^{\mathrm{a}}$ & $77.7^{\mathrm{a}}$ \\
\hline 6654 & 50 & $3^{\mathrm{a}}$ & 9 & $66.7^{\mathrm{a}}$ & $77.7^{\mathrm{a}}$ \\
\hline 6654 & 75 & $3^{\mathrm{a}}$ & 7 & $66.7^{\mathrm{a}}$ & $71.4^{\mathrm{a}}$ \\
\hline 6654 & 80 & $3^{\mathrm{a}}$ & 9 & $66.7^{\mathrm{a}}$ & $77.8^{\mathrm{a}}$ \\
\hline 6654 & 90 & $3^{\mathrm{a}}$ & 11 & $66.7^{\mathrm{a}}$ & $81.8^{\mathrm{a}}$ \\
\hline 6653 & 0 & $3^{\mathrm{a}}$ & $8^{\mathrm{b}}$ & $100^{\mathrm{ab}}$ & $62.5^{\mathrm{ab}}$ \\
\hline 6653 & 25 & $3^{\mathrm{a}}$ & $7^{\mathrm{b}}$ & $100^{\mathrm{ab}}$ & $57.1^{\mathrm{ab}}$ \\
\hline 6653 & 50 & $3^{a}$ & $6^{\mathrm{b}}$ & $100^{\mathrm{ab}}$ & $50.0^{\mathrm{ab}}$ \\
\hline 6653 & 75 & $3^{\mathrm{a}}$ & $6^{\mathrm{b}}$ & $100^{\mathrm{ab}}$ & $50.0^{\mathrm{ab}}$ \\
\hline 6653 & 80 & $3^{\mathrm{a}}$ & $8^{\mathrm{b}}$ & $100^{\mathrm{ab}}$ & $62.5^{\mathrm{ab}}$ \\
\hline 6653 & 90 & $3^{a}$ & $10^{\mathrm{b}}$ & $100^{\mathrm{ab}}$ & $70.0^{\mathrm{ab}}$ \\
\hline
\end{tabular}

*Small cloud patch near image corner (no impact on persons' view).

${ }^{\text {a }}$ Statistics corrected due to the assumption that $\mathrm{P} 45$ is a single person,

${ }^{\mathrm{b}}$ Statistics corrected due to person split into 2-4 adjacent segments (overlapping stripes—-see Sect. 3)

blurriness above which (when transparency becomes very low) a number of false hits increases again. This can be explained by too intensive reduction of clarity and a consequent removal of too many details, including persons. In the context of our exercise, such a noise reduction is particularly meaningful because persons who took part in the field experiment wore blue and red jackets, and the signal of their clothes remained strong.

\section{Conclusions}

This paper shows that the presence of transparent clouds in UAV-taken oblique aerial images may improve the performance of the automated human detection using the nested k-means method. Although no impact of cloudiness on person detection rates were reported, clouds were found to reduce false hit rates and, as a consequence, to reduce overrepresentation of sites suggested to be searched. Sensitivity analysis, in which the clarity of UAV-taken aerial images was artificially deteriorated by superimposing white layers with different transparencies to imitate the effect naturally caused by clouds, confirmed that the reduced clarity may improve the performance of the method. The decrease in the number of false hits was found for intermediate transparencies (25-75\%), and the number of false hits tended to grow when clarity of images was highly reduced (superimposed white layers with 80-90\% transparency).

The results may have a considerable practical potential-in a cloudy weather UAVs may be manoeuvered to fly at low altitudes so that cloud cover does not constrain the view but gives a transparent blurred picture of terrain. Such a flight planning for SAR purposes may, according to our preliminary study published in this paper, improve the performance of the automated human detection algorithms. Alternatively, artificial filtering to simulate the effect of transparent clouds may be considered. Usually the presence of clouds is considered to constrain the usefulness of different remote sensors (e.g. O'Donnell 1999; Woodell et al. 2015), but our results show that under specific circumstances the effect of clouds can be considered as a virtue. Although the findings are promising, further studies are required to investigate similar relationships when different person detection algorithms are employed. They may include either the investigation based on a bigger set of cloud-influenced images or the comparison of clean images with photographs artificially blurred by image filters. At present, the results may therefore be method-specific and may inherit certain limitations of the algorithms themselves. In the context of the nested k-means approach, discrepancies between snow-covered and snow-free terrain concerned overrepresentation, with high values of the 
POSSTBS statistics recorded in winter (Niedzielski et al. 2017). Therefore, it is likely that transparent clouds may reduce differences between the performance of the method in various seasons of year.

\section{Acknowledgements}

The research was financed by the Ministry of Science and Higher Education of Poland through the project no. IP2014 032773. The authors thank Joanna Remisz and Małgorzata Świerczyńska-Chlaściak for technical help in operating a UAV. The participants of the field exercise-Jacek Ślopek, Krzysztof Parzóch and Monika Fila-who simulated to be lost in the wilderness are also acknowledged. The authors are also indebted to Lubomir Leszczyński and Katarzyna Mecina, both representing Świeradów Forest Inspectorate, who supported our fieldwork and observational campaigns.

Open Access This article is distributed under the terms of the Creative Commons Attribution 4.0 International License (http:// creativecommons.org/licenses/by/4.0/), which permits unrestricted use, distribution, and reproduction in any medium, provided you give appropriate credit to the original author(s) and the source, provide a link to the Creative Commons license, and indicate if changes were made.

\section{REFERENCES}

Błaś, M., Sobik, M., Quiel, F., \& Netzel, P. (2002). Temporal and spatial variations of fog in the Western Sudety Mts, Poland. Atmospheric Research, 64, 19-28.

Djuricic, A., \& Jutzi, B. (2013). Supporting UAVs in low visibility conditions by multiple-pulse laser scanning devices. The International Archives of the Photogrammetry Remote Sensing and Spatial Information Sciences, XL-1/W1, 93-98.

Doherty, P., \& Rudol, P. (2007). A UAV search and rescue scenario with human body detection and geolocalization. In A. O. Mehmet \& J. Thornton (Eds.), AI 2007: Advances in artificial intelligence (pp. 1-13). Berlin: Springer.

Flynn, H., \& Cameron, S. (2013). Multi-modal people detection from aerial video. In R. Burduk, K. Jackowski, M. Kurzynski, M. Wozniak, \& A. Zolnierek (Eds.), Proceedings of the 8th international conference on computer recognition systems CORES 2013 (pp. 815-824). Berlin: Springer.

Goodrich, M. A., Morse, B. S., Engh, C., Cooper, J. L., \& Adams, J. A. (2009). Towards using unmanned aerial vehicles (UAVs) in wilderness search and rescue: Lessons from field trials. Interaction Studies, 10, 453-478.
Goodrich, M. A., Morse, B. S., Gerhardt, D., \& Cooper, J. L. (2008). Supporting wilderness search and rescue using a cameraequipped mini UAV. Journal of Field Robotics, 25, 89-110.

Gretchen, K. E. (2004). Epidemiology of wilderness search and rescue in New Hampshire, 1999-2001. Wilderness and Environmental Medicine, 15, 11-17.

Gultepe, I., Pearson, G., Milbrandt, J. A., Hansen, B., Platnick, S., Taylor, P., et al. (2009). The fog remote sensing and modeling field project. Bulletin of the American Meteorological Society, 90, 341-360.

Jurecka, M., \& Niedzielski, T. (2017). A procedure for delineating a search region in the UAV-based SAR activities. Geomatics Natural Hazards and Risk, 8, 53-72.

Marconi, L., Leutenegger, S., Lynen, S., Burri, M., Naldi, R., \& Melchiorri, C. (2013). Ground and aerial robots as an aid to alpine search and rescue: Initial SHERPA outcomes. In 2013 IEEE International symposium on safety, security, and rescue robotics (SSRR). Linkoping, 2013, 1-2. https://doi.org/10.1109/ SSRR.2013.6719381.

Miller, A., Babenko, P., Hu, M., \& Shah, M. (2008). Person tracking in UAV video. In R. Stiefelhagen, R. Bowers, \& J. Fiscus (Eds.), Multimodal technologies for perception of humans. Lecture notes in computer science 4625 (pp. 215-220). Heidelberg: Springer.

Molina, P., Colomina, I., Vitoria, T., Silva, P. F., Skaloud, J., Kornus, W., et al. (2012). Searching lost people with UAVS: The system and results of the close-search project. International Archives of the Photogrammetry Remote Sensing and Spatial Information Sciences, 39(B1), 441-446.

Niedzielski, T., Jurecka, M., Miziński, B., Remisz, J., Ślopek, J., Spallek, W., et al. (2018). A real-time field experiment on search and rescue operations assisted by unmanned aerial vehicles. Journal of Field Robotics, https://doi.org/10.1002/rob.21784.

Niedzielski, T., Jurecka, M., Stec, M., Wieczorek, M., \& Miziski, B. (2017). The nested k-means method: A new approach for detecting lost persons in aerial images acquired by unmanned aerial vehicles. Journal of Field Robotics, 34, 1395-1406.

Oakley, J. P., \& Satherley, B. L. (1998). Improving image quality in poor visibility conditions using a physical model for contrast degradation. IEEE Transactions on Image Processing, 7, 167-179.

O'Donnell, J. E. D. (1999). Operational ocean search and rescue using AVHRR: Cloud limitations. Journal of Atmospheric and Oceanic Technology, 16, 388-393.

Rudol, P., \& Doherty, P. (2008). Human body detection and geolocalization for UAV search and rescue missions using color and thermal imagery. In Aerospace conference (Ed.), 2008 (pp. 1-8). Big Sky: Institute of Electrical and Electronics Engineers.

Silvagni, M., Tonoli, A., Zenerino, E., \& Chiaberge, M. (2017). Multipurpose UAV for search and rescue operations in mountain Avalanche events. Geomatics Natural Hazards and Risk, 8, 18-33.

Steinvall, O., Olsson, H., Bolander, G., Carlsson, C. \& Letalick, D. (1999). Gated viewing for target detection and target recognition. In Proceedings of SPIE (vol. 3707, pp. 432-448).

Sumimoto, T., Kuramoto, K., Okada, S., Miyauchi, H., Imade, M., Yamamoto, \& H., Arvelyna, Y. (2000). Detection of a particular object from environmental images under various conditions. In 
2000 IEEE international symposium on industrial electronics, 2000 (col. 2, pp. 590-595), Cholula, Puebla.

Van Tilburg, V. (2017). First report of using portable unmanned aircraft systems (drones) for search and rescue. Wilderness and Environmental Medicine, 28, 116-118.

Woodell, G., Jobson, D.J., Rahman, Z., \& Hines, G. (2015). Enhancement of imagery in poor visibility conditions. In
Proceedings of SPIE 5778, Sensors, and Command, Control, Communications, and Intelligence (C3I) Technologies for Homeland Security and Homeland Defense IV. https://doi.org/10. 1117/12.601965.

Yuan, H.-Z., Zhang, X.-Q., \& Feng, Z.-L. (2010). Horizon detection in foggy aerial image. In International Conference on Image Analysis and Signal Processing (pp. 191-194). Zhejiang.

(Received October 23, 2017, revised June 15, 2018, accepted June 20, 2018, Published online July 6, 2018) 